\title{
Safety evaluation of LD27-2 WHPB platform based on rod pumping
}

\author{
Yanqun $\mathrm{Yu}^{1} \cdot$ Xiaoguang Huang ${ }^{2} \cdot$ Zhiming Yin $^{3}$
}

Received: 8 April 2020 / Accepted: 8 June 2020 / Published online: 16 June 2020

(c) The Author(s) 2020

\begin{abstract}
The development of heavy oil with high efficiency is a worldwide difficulty for offshore oil field. The technology of rod pumping provides a possible effective way for offshore heavy oil thermal recovery, but the safety of working platform is the prerequisite for the implementation of this new technology. In this paper, the mechanical model of LD27-2 WHPB platform is established, and the safety performance of the platform under hydraulic pumping unit (HPU) load is evaluated. The distribution of the combined HPU load accords with the classical probability model. When the HPUs are all synchronous, the combined load reaches its maximum. The finite element-based platform safety analysis under the extreme condition is carried out. Under the combined action of wave current, wind load and the extreme HPU load, the maximum stress of the jacket is $83.2 \mathrm{MPa}$, and the safety coefficient is 4.33 , indicating the overall strength of LD27-2 WHPB platform meets the safety requirement.
\end{abstract}

Keywords Offshore platform $\cdot$ Rod pumping $\cdot$ Hydraulic pumping unit $\cdot$ Joint distribution of extreme $\cdot$ Mechanical properties

\section{Introduction}

It is estimated that the offshore oil resources worldwide are about $1 \times 10^{11} \mathrm{t}$, of which the proven reserves reach to $3.8 \times 10^{10} \mathrm{t}$, and $34 \%$ of oil production comes from the ocean (Zhou et al. 2015). According to the IHS statistics, the offshore oil and gas reserves, as well as production of the five major multinational oil companies, namely Exxon Mobil, Chevron, Total, BP Amoco and Shell Group of Companies, have reached about $50 \%$ of the total reserves and production (Yan 2016). At present, the major oil exploration will gradually shift from land to offshore (Shariatinia et al. 2013; Bodhayan et al. 2016). By the end of 2013, 82 offshore oil fields and eight gas fields as well as four offshore oil-gas production bases have been developed in China. The main production areas have gradually shifted from the Nanhai oil

Yanqun $\mathrm{Yu}$

yuyq_hdpu@126.com

1 National Engineering Laboratory of Offshore Geophysical and Exploration Equipment, China University of Petroleum, Shandong 266580, China

2 College of Pipeline and Civil Engineering, China University of Petroleum, Qingdao, China

3 CNOOC Research Institute Co., Ltd., Beijing, China field in the last century to the Bohai oil field (Guo et al. 2010), and Bohai oil field has become a national important energy base. There are 42 oil and gas fields in production, of which heavy oil reserves account for about $85 \%$ of the total proved crude oil reserves (Tang et al. 2011), and the large oil fields (geological reserves greater than 100 million tons) are almost heavy oil ones. Limited by the size of offshore platform, the current drainage and recovery technology and its design habits, submersible electric pumps are the main lifting equipments. However, the low temperature resistance and structural factors of the submersible electric pump unit restrict either the selection of heavy oil thermal recovery method or the selection of the implantation temperature. To overcome this shortage, the small hydraulic pumping units for offshore platforms have been designed and successfully applied to the wellhead and downhole equipment, and the further technical difficulties have also been solved (Yu et al. 2016). A new rod pumping recovery technology named "steam stimulation along with conventional sucker rod pumping" for offshore heavy oil recovery has gradually formed, thereby gaining high-efficient recovery onshore ( $\mathrm{Yu}$ et al. 2016; Chang et al. 2017).

In order to accelerate the development of offshore steam stimulation technology, it is preferred to carry out the field pilot test on steam stimulation technology in the LD27-2 
oil field to promote the large-scale development of offshore heavy oil thermal recovery ( $\mathrm{Li}$ et al. 2016). For the LD27-2 jacket-type fixed platform, the safety of platform is the premise for the implementation of offshore rod pumping technology. The new technology adds rod pumping equipment and herein additional load on the offshore platform, which definitely changed the loading status of the former platform. Thus, it is of vital importance to research on the safety performance of the platform under the joint distribution of limit load. In this paper, the mechanical model of LD27-2 WHPB platform is established, and the finite element (FE) analysis of the platform under the extreme condition is carried out to evaluate its safety.

\section{Force analysis of the platform}

The LD27-2 WHPB platform is a four-leg steel jacket platform which integrates the drilling, completion, workover and production. The diameter of the four main piles is $1829 \mathrm{~mm}$, and the platform design depth is $22.3 \mathrm{~m}$. The hoisting weights of the deck and jacket are $2700 \mathrm{t}$ and $1000 \mathrm{t}$, respectively. The wellhead area locates in the central north of the deck, with 20 pits in a $4 \times 5$ array. The distance between the wellheads is $1.8 \mathrm{~m} \times 2.0 \mathrm{~m}$. Schematic diagram of LD27-2 WHPB platform installation for pumping unit is shown in Fig. 1.

The fixed jacket platform is the most primary structural form in the Bohai oil field. Static and dynamic models have been used to assess the safety of offshore platforms (Ou et al. 2003; Chandrasekaran and Jain 2002; Yasser et al. 2003). However, the fixed jacket platform has a lower natural frequency, and the dynamic response is susceptible to the marine environmental loads (Mangal et al. 2001; Ren and Zong 2004). Therefore, in the study of static and dynamic analysis and safety assessment of offshore platforms, the effective treatment of environmental loads is a problem that cannot be ignored.

The hoisting weight of deck is applied to the four main legs as concentrated loads. Force diagram of the platform under wave flow load, wind load and HPU load is shown in Fig. 2, where $F_{\mathrm{T}}$ is the weight of deck dead, $F_{\mathrm{P}}$ is the HPU

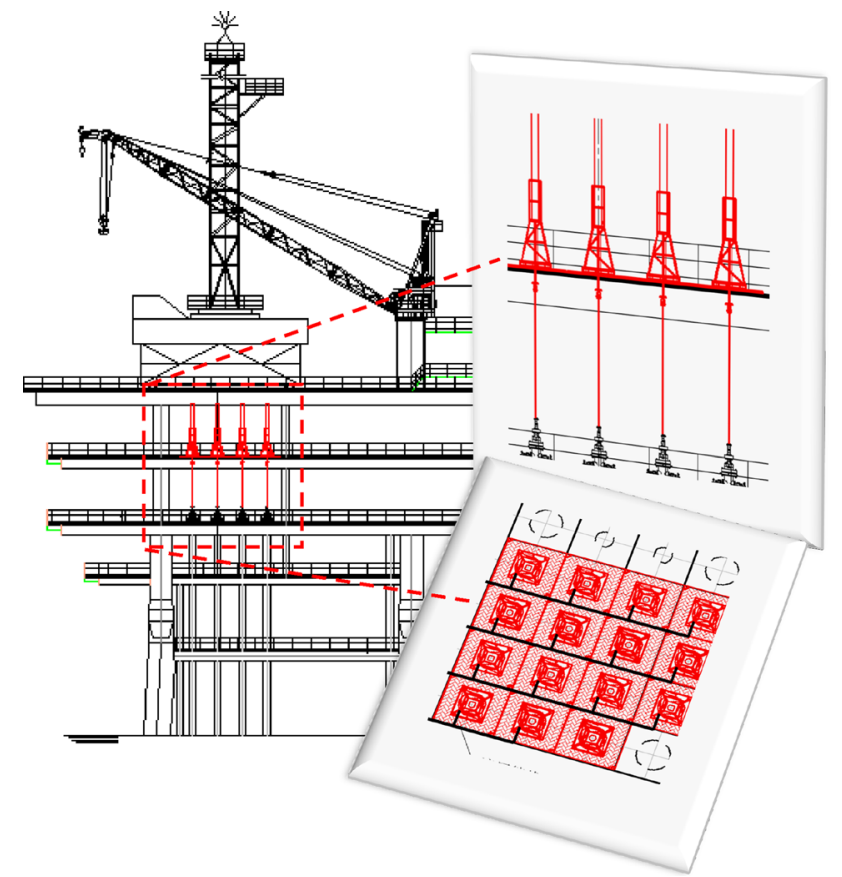

Fig. 1 Schematic diagram of LD27-2 WHPB platform installation for pumping unit

uniform load. The wave flow load $F_{\mathrm{H}}$ is applied to the legs according to the wave direction.

\section{Marine environmental load}

The structural response of offshore platform can be regarded as a function of the environmental factors such as wave height, wind speed and surface velocity. $G\left(x_{1}, x_{2}, x_{3}\right)$ is used to represent the three-dimensional Gumbel nested logic distribution of the random vector $\left(x_{1}, x_{2}, x_{3}\right)$, of which the univariate margin can be expressed as:

$H_{i}\left(x_{i}\right)=\exp \left\{-\exp \left[-\frac{x_{i}-\mu_{i}}{\sigma_{i}}\right]\right\}, i=1,2,3$

where $\mu_{i}$ and $\sigma_{i}$ represent the location parameter and dimension parameter, respectively.

And the equation of the three-dimensional Gumbel nested logic model is written as

$G\left(x_{1}, x_{2}, x_{3}\right)=\exp \left\{-\left[\left(\left(-\ln H_{1}\left(x_{1}\right)\right)^{\frac{1}{\alpha \beta}}+\left(-\ln H_{2}\left(x_{2}\right)\right)^{\frac{1}{\alpha \beta}}\right)^{\beta}+\left(-\ln H_{3}\left(x_{3}\right)\right)^{\frac{1}{\alpha}}\right]^{\alpha}\right\}$

load including dead weight, $F_{\mathrm{W}}$ is the load of wind and $F_{\mathrm{H}}$ is load of wave flow.

The deck dead weight $F_{\mathrm{T}}$ is distributed on the four main pile legs as concentrated load. The HPU load and wells load $F_{\mathrm{P}}$ act on the respective wellhead crossbeams. The wind load $F_{\mathrm{W}}$ acts on the different elevations of the platform as the where $\alpha$ and $\beta$ are the relevant parameters, and $0 \leq \alpha, \beta \leq 1$.

Based on the three-dimensional Gumbel nested logic distribution theory (Xu 2013), the design values of wave height $H$, wind speed $w$ and surface velocity $v$ which are seen as 


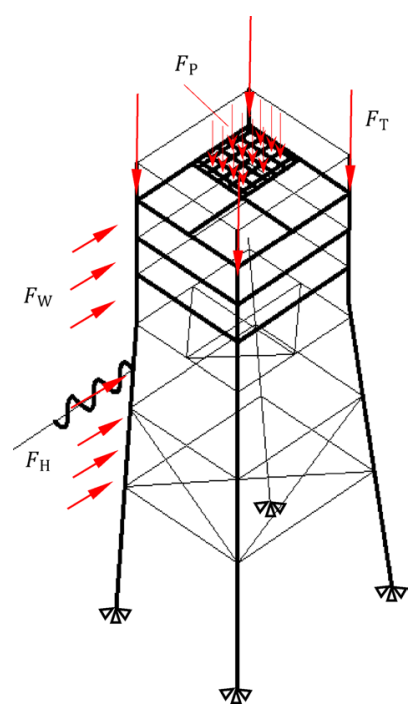

Fig. 2 Force diagram of the platform

the main extrema of the return period are shown in Fig. 3, respectively.

From Fig. 3, it can be seen that when surface velocity $v$ is the main extremum, the design values of each return period are greater. So it is relatively stricter to evaluate the platform strength with the surface velocity $v$ as the main extremum. According to the Chinese Offshore Platform Design Specification, the extremum of the 50-year return period when the surface velocity $v$ reaches its maximum is listed in Table 1 (Feng et al. 2008).

\section{Wave flow load}

For a fixed jacket platform, where the wavelength is much greater than the linkage diameters $(L / D>0.2)$. Morison's formula can be used to calculate the wave forces on the linkages. The Morison theory holds that the waves mainly have both viscous effect and mass loading effect on the cylinders. Force diagram of a single pile leg is shown in Fig. 4.

The horizontal wave force on a single pile (Wang 2013) is:

$$
\begin{aligned}
F_{H}= & \frac{1}{2} C_{\mathrm{D}} \rho A u_{x}\left|u_{x}\right|+C_{M} \rho \overline{V_{0}} \frac{\partial u_{x}}{\partial t}=\frac{1}{2} \int_{0}^{d+} C_{\mathrm{D}} \rho D u_{x}\left|u_{x}\right| d_{z} \\
& +\int_{0}^{{ }_{+}+{ }^{H} / 2} C_{M} \rho \frac{\pi D^{2}}{4} \frac{\partial u_{x}}{\partial t} d_{z}
\end{aligned}
$$

where $u_{x}$ is the horizontal speed of the wave water particle at height $z$ of the cylinder central axis, $\mathrm{m} / \mathrm{s} ; \frac{\partial u_{x}}{\partial t}$ is the horizontal acceleration of water particle, $\mathrm{m} / \mathrm{s}^{2} ; A$ is the projected area

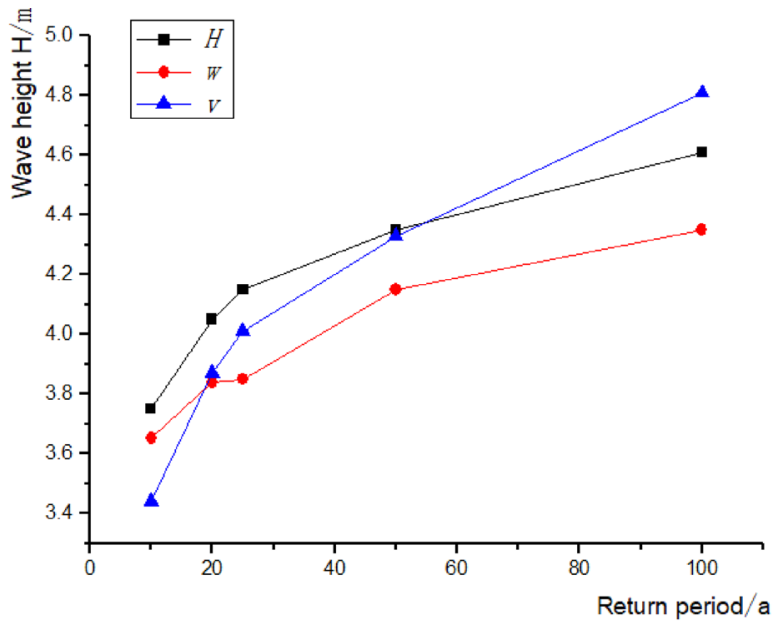

(a) Wave height $H$ under different main extrema

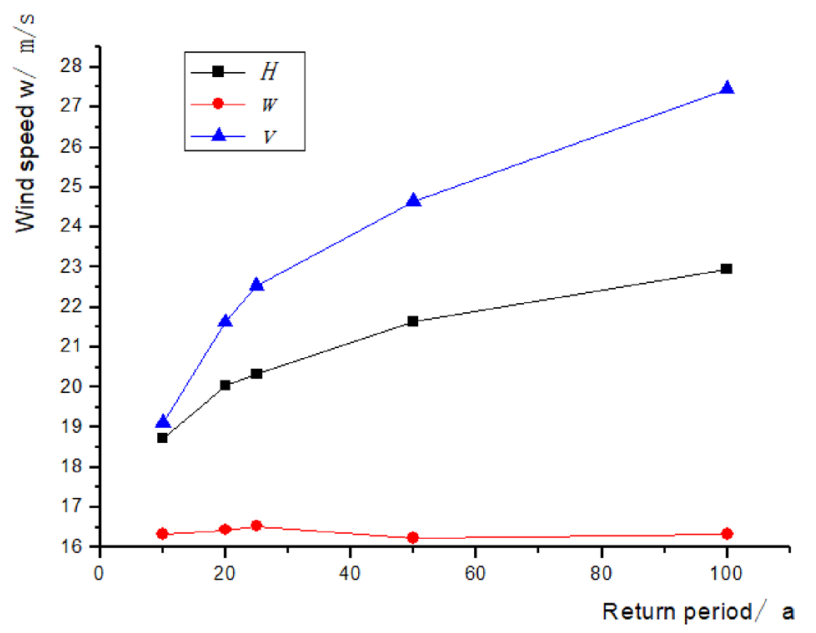

(b) Wind speed $w$ under different main extrema

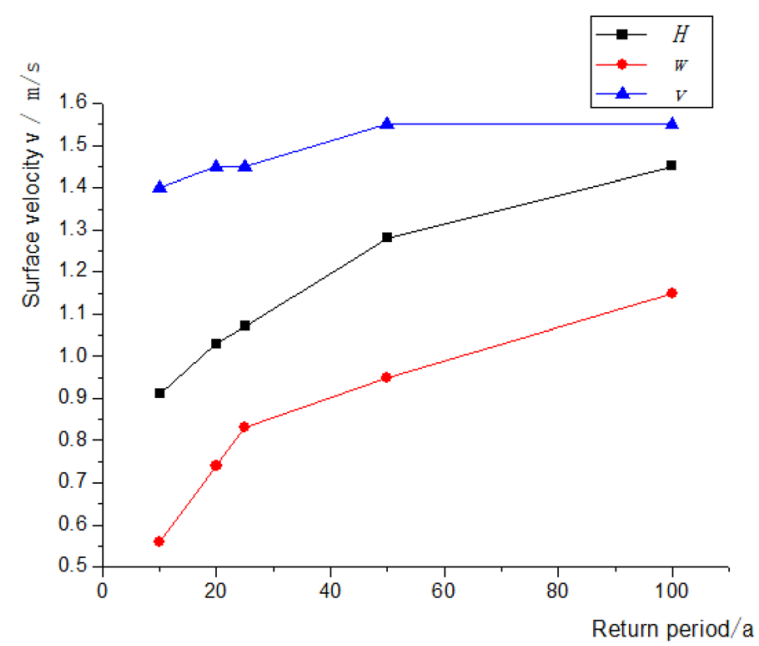

(c) Surface velocity $v$ under different main extrema

Fig. 3 Wave parameters under different main extrema 
Table 1 The extrema of the 50 -year return period when the surface velocity $v$ reaches the maximum

\begin{tabular}{|c|c|c|c|c|c|c|}
\hline \multicolumn{3}{|c|}{ Surface velocity $(\mathrm{m} / \mathrm{s})$} & \multicolumn{2}{|l|}{ Wave } & \multicolumn{2}{|c|}{ Wind speed $(\mathrm{m} / \mathrm{s})$} \\
\hline$V_{\text {sur }}$ & $V_{\text {mid }}$ & $V_{\text {bot }}$ & $\mathrm{Hm}(\mathrm{m})$ & $\operatorname{Tm}(\mathrm{s})$ & $5-\mathrm{s}$ & $1-\min$ \\
\hline 1.672 & 1.575 & 1.251 & 7.9 & 6.5 & 37.0 & 30.8 \\
\hline
\end{tabular}

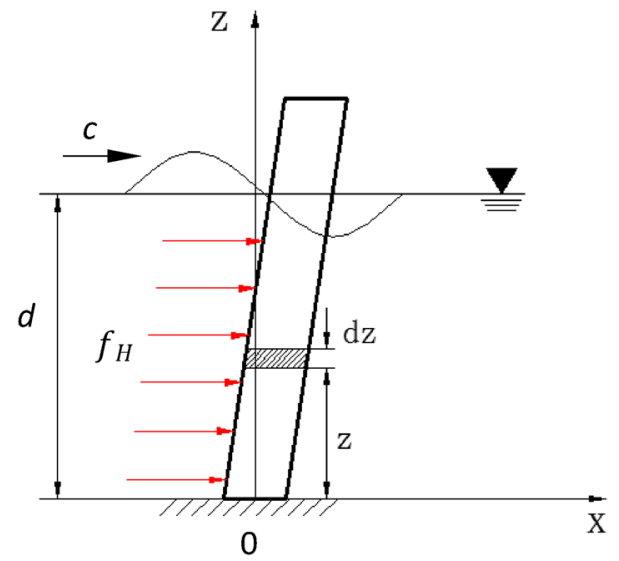

Fig. 4 Force diagram of a single pile leg

of unit column height on the direction vertical to the wave, $\mathrm{m}^{2} ; \overline{V_{0}}$ is the drainage volume of unit column height, $\mathrm{m}^{3}$; $D$ is the diameter of leg, $\mathrm{m} ; \rho$ is the seawater density, $\mathrm{kg} /$ $\mathrm{m}^{3} ; C_{\mathrm{D}}$ is the drag force coefficient, $C_{M}$ is the weight coefficient; and in accordance with Rules for the Classification and Construction of Fixed Offshore Platforms of China, $C_{\mathrm{D}}=1.2, C_{M}=2.0$.

The total horizontal wave moment of the entire leg to the seabed is:

$M_{H}=\frac{1}{2} \int_{0}^{H+\eta_{/ 2}} C_{\mathrm{D}} \rho D u_{x}\left|u_{x}\right| z d_{z}+\int_{0}^{H+\eta_{/ 2}} C_{M} \rho \frac{\pi D^{2}}{4} \frac{\partial u_{x}}{\partial t} z d_{z}$

Based on the platform structure, the maximum horizontal wave moment of the entire leg to the seabed is $1.452 \times 10^{3} \mathrm{kN} \mathrm{m}$, according to Table 1 and Eq. (4).

\section{Wind load}

Waves in Bohai Sea are mainly caused by gales, and swells and mixed waves only account for a small proportion. Therefore, there is a good correspondence between winds and waves. The amplitude of the waves mainly depends on the wind speeds. The standard wind speed at offshore platforms is about the average speed of wind at $10 \mathrm{~m}$ above sea level, with a 50-year return period and time interval less than $1 \mathrm{~min}$.

The wind load on the platform $F_{\mathrm{W}}$ is

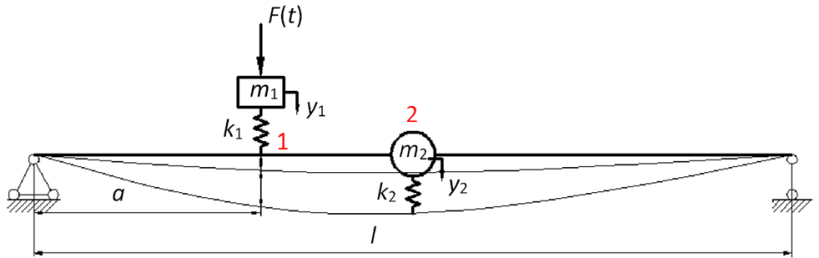

Fig. 5 Dynamic model of single pumping unit

$F_{\mathrm{W}}=K \cdot K_{Z} \cdot P_{0} \cdot A$

where $K$ is the shape coefficient of wind load; $K_{Z}$ is the height variation coefficient of sea wind pressure, which can be referred to GB50009-1012; $P_{0}$ is the basic wind pressure, $\mathrm{Pa}$; and $A$ is the pressure area, $\mathrm{m}^{2}$.

The basic wind pressure on the platform is calculated as:

$P_{0}=\alpha V_{t}^{2}$

where $\alpha$ is the coefficient of wind pressure, here as $0.613 \mathrm{~N} \mathrm{~s}^{2} / \mathrm{m}^{4}$, and $V_{t}$ is the designed wind speed at the time interval of $t$ mins, $\mathrm{m} / \mathrm{s}$.

\section{Study on additional loads on the platform due to HPU}

\section{Dynamic analysis of single unit: partial platform system of pumping unit}

Considering the influence of a single pumping unit on the platform, the platform support can be reduced to a mass beam. The corresponding kinetic model is shown in Fig. 5, where $F(t)$ is the input load of hanging point of the pumping unit, $l$ is the length of supporting beam for the platform, $a$ is the installment position of pumping unit, $m_{1}$ is the mass of pumping unit, $m_{2}$ is the mass of supporting beam, $k_{1}$ is the equivalent stiffness of the pumping unit, $k_{2}$ is the equivalent stiffness of the support beam of the platform, $y_{1}$ is the mass center displacement of the pumping unit (static equilibrium point as the origin) and $y_{2}$ is the mass center displacement of the supporting beam (static equilibrium point as the origin). 
The system of Fig. 5 belongs to the two-degree-of-freedom undamped forced vibration system. According to the force of the mass point $\mathrm{m}_{1}$ and $\mathrm{m}_{2}$, we have:

$\left\{\begin{array}{l}-m_{1} \ddot{y}_{1}=F(t)-k_{1}\left(y_{1}-\delta_{21} y_{2}\right) \\ -m_{2} \ddot{y}_{2}=k_{1}\left(y_{1}-\delta_{21} y_{2}\right)-k_{2} y_{2}\end{array}\right.$

where $\delta_{21}$ is the dynamic displacement of concentrated mass converting from position 2 to position 1 .

Using structural mechanics theory, the dynamic displacement can be obtained as

$\delta_{21}=\frac{16 a^{2}(l-a)^{2}}{l^{4}}$

And the natural frequency of the system is:

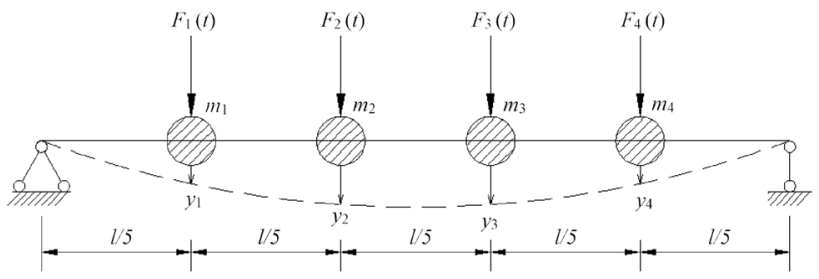

Fig. 7 Dynamic model of single-line pumping unit of LD27-2 WHPB platform

$\omega_{j n}=1 / \sqrt{\frac{5}{\omega_{j n 1}^{2}}}$

$\omega_{n 1,2}=\sqrt{\frac{k_{1} m_{2}+\left(k_{1}+k_{2}\right) m_{1}}{2 m_{1} m_{2}} \mp \frac{1}{2} \sqrt{\left(\frac{k_{1} m_{2}+\left(k_{1}+k_{2}\right) m_{1}}{m_{1} m_{2}}\right)^{2}-4 \frac{k_{1}\left(k_{1}+k_{2}\right)-\delta_{21}^{2} k_{1}^{2}}{m_{1} m_{2}}}}$

\section{Dynamic analysis of entire platform system of pumping unit}

As shown in Fig. 1, the wellhead area of LD27-2 WHPB locates in the central north of the deck, with 20 pits in a $4 \times 5$ array. Two installation positions of the single-well pumping unit for target platform are shown in Fig. 6.

The platform support is simplified to a combination of concentrated mass and massless beam. Dynamic model of single-line pumping unit is shown in Fig. 7:

The natural frequency of the system in Fig. 7 is:

$\omega_{j n 1}=1 / \sqrt{\frac{1}{\omega_{j n 11}^{2}}+\frac{1}{\omega_{j n 22}^{2}}+\frac{1}{\omega_{j n 33}^{2}}+\frac{1}{\omega_{j n 44}^{2}}}$

Comparing with Fig. 6, we can obtain $\omega_{j n 11}=\omega_{j n 44}, \omega_{j n 22}=\omega_{j n 33}$.

So, the natural frequency of entire platform system of pumping unit ( $4 \times 5$ array) can be rewritten as:
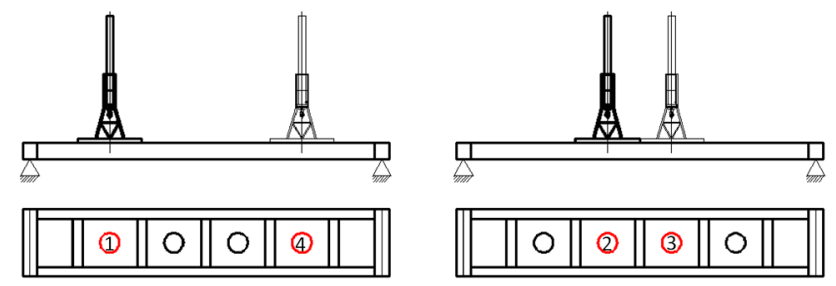

Fig. 6 Schematic diagram of single-well installation
The pumping unit is connected with the sucker rod string through hydraulic cylinder. The working force of the hydraulic cylinder is the excitation source of the above two subsystems. In accordance with the requirements of produced fluids of oil well, the pumping speed is $2-5$ times per min, i.e., the excitation frequency is $0.033-0.083 \mathrm{~s}^{-1}$. The relationship between the subsystems and excitation frequency is shown in Fig. 8.

In Fig. 8, code names represent: 1-pumping unit excitation; 2-sucker rod pillar system; 3-single unit and support subsystem of position 1 or 4 system; 4-single unit and support subsystem of position 2 or 3; 5-single-line

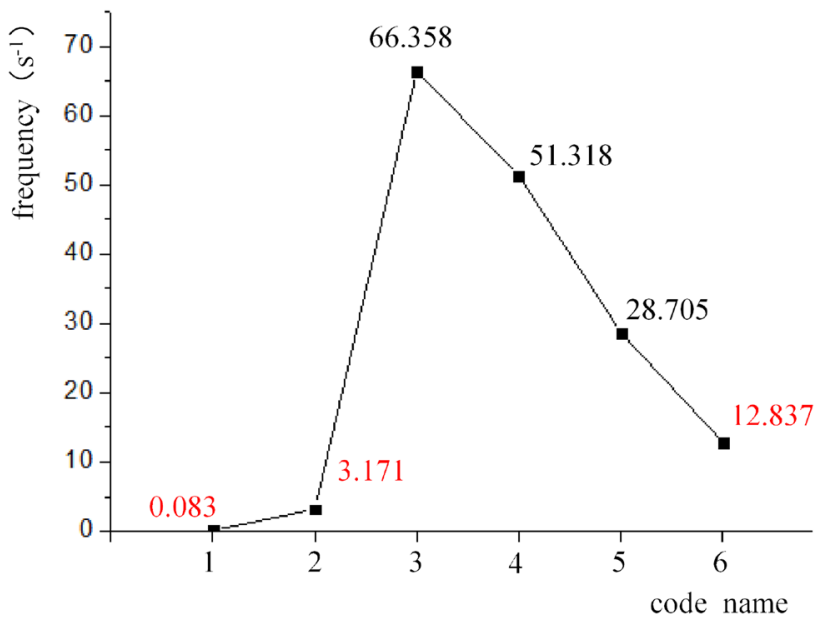

Fig. 8 Relationship between multibody system of LD27-2 WHPB platform and excitation frequency 
pumping unit and beam support subsystem; 6-full pumping unit and wellhead deck beam system.

From Fig. 8, the natural frequencies of the two subsystems and the excitation frequency differ by more than five times, which means no resonance phenomenon appearing in the rod production system of offshore platform during the working process. Therefore, the loading of pumping unit system on the platform can be superimposed by a single loading.

\section{Additional loads on the platform due to pumping unit}

According to the motion characteristics of pumping units, for a single well, the force on the platform of an operating pumping unit is:

$F_{i j}(t)= \begin{cases}F_{\mathrm{d} i j}+\frac{20\left(F_{\mathrm{u} i j}-F_{\mathrm{dij}}\right)}{T_{i j}} t, & (k-1) T_{i j} \leq t<\frac{(20 k-19) T_{i j}}{20} \\ F_{\mathrm{u} i j}, & \frac{(20 k-19) T_{i j}}{20} \leq t<\frac{(2 k-1) T_{i j}}{2} \\ F_{\mathrm{u} i j}-\frac{20\left(F_{\mathrm{u} i j}-F_{\mathrm{dij}}\right)}{T_{i j}}\left(t-\frac{T_{i j}}{2}\right), & \frac{(2 k-1) T_{i j}}{2} \leq t<\frac{(20 k-9) T_{i j}}{20} \\ F_{\mathrm{d} i j}, & \frac{(20 k-9) T_{i j}}{20} \leq t<k T_{i j}\end{cases}$

where $F_{i j}$ is the pumping unit load of well $(i, j), \mathrm{kN} ; F_{\mathrm{d} i j}$ is the maximum load in the downstroke, $\mathrm{kN} ; F_{\mathrm{u} i j}$ is the maximum load in the upstroke, $\mathrm{kN} ; T_{i j}$ is the motion period of pumping unit, $\mathrm{s}$; and $k$ is the natural number.

If the highest yield value after steam stimulation is considered, the pumping speed is $5 \mathrm{~min}^{-1}$ and all wells are considered to be working under extreme conditions. A single well period is divided into 20 equal periods, i.e., $0.6 \mathrm{~s}$ for each. The wells within the same $0.6 \mathrm{~s}$ period are considered synchronized. The combination of working conditions is a typical classical probability model as the wells are mutually independent from each other. Any working conditions combination of the 20 pumping units is a little probability event. When the 20 units of the platform are fully synchronized, from Eq. 12, the force of the pumping units on the platform can be modified as:

$F(t)=20 \begin{cases}F_{\mathrm{d}}+\frac{5\left(F_{\mathrm{u}}-F_{\mathrm{d}}\right)}{3} t, & 12(k-1) \leq t<0.6(20 k-19) \\ F_{\mathrm{u}}, & 0.6(20 k-19) \leq t<6(2 k-1) \\ F_{\mathrm{u}}-\frac{5\left(F_{\mathrm{u}}-F_{\mathrm{d}}\right)}{3}(t-6), & 6(2 k-1) \leq t<0.6(20 k-9) \\ F_{\mathrm{d}}, & 0.6(20 k-9) \leq t<12 k\end{cases}$

When the wells are completely desynchronized, the force of the pumping unit to the platform is:
$F(t)= \begin{cases}F_{\mathrm{d}}+\frac{5\left(F_{\mathrm{u}}-F_{\mathrm{d}}\right)}{3} t, & 0 \leq t<6 \\ 10\left(F_{\mathrm{u}}+F_{\mathrm{d}}\right), & 6 \leq t\end{cases}$

The maximum polished rod load of the platform is $F_{\mathrm{u}}=6 \times 10^{3} \mathrm{kN}$ in the upstroke and $F_{\mathrm{u}}=3 \times 10^{3} \mathrm{kN}$ in the downstroke. From Eq. 14, when the wells are completely desynchronized, the load on the platform stays at $10\left(F_{\mathrm{u}}+F_{\mathrm{d}}\right)$ after the HPUs run stable, and $75 \%$ of the load when the wells are fully synchronized.

Based on the independence between the wells, three kinds of HPU combinations are randomly designed. The loads on the platform are shown in Fig. 9.

In Fig. 9, the abscissa is time $t(/ \mathrm{s})$ and the ordinate is the combined load $F(t)(/ \mathrm{kN})$. From front to back, the number of synchronized wells increases. From Fig. 9, the combined load of the HPUs on the platform under random conditions accords approximately with a sine curve with a period of $12 \mathrm{~s}$. To sum up, the combined load on the whole system is the largest when the 20 units are completely synchronized. And a stable load can be obtained when the system is stabilized. In other conditions, the load is applied to the platform in different waveforms with a period of $12 \mathrm{~s}$ after stabilizing. When the 20 pumping units are fully synchronized, the combined load is the largest and the load difference between the upstroke and downstroke reaches the maximum. Therefore, the fully synchronized condition is used in the FE analysis of the platform.

\section{FE analysis of the platform under combined load}

\section{Establishment of finite element model of the platform}

The finite element model is shown in Fig. 10. The underwater components, abovewater component, deck beam and deck surface are simulated by PIPE59 unit, PIPE16 unit, BEAM188 unit and SHELL63 unit, respectively. Other ancillary components, upper equipment and simplified components are simulated by mass unit MASS21. The finite element model of LD27-2 WHPB platform is a combined model of space plate, pipe and beam. The legs are defined as the boundary conditions, without considering the interaction between sediment and legs. The sections of the main piles which are 6-8 times the pile diameter beneath the sediment surface can be considered as the fixed ends.

\section{FE analysis of the platform main structure}

In this section, the structural mechanical responses of the flatform under HPU load as shown in Fig. 2 are analyzed. 

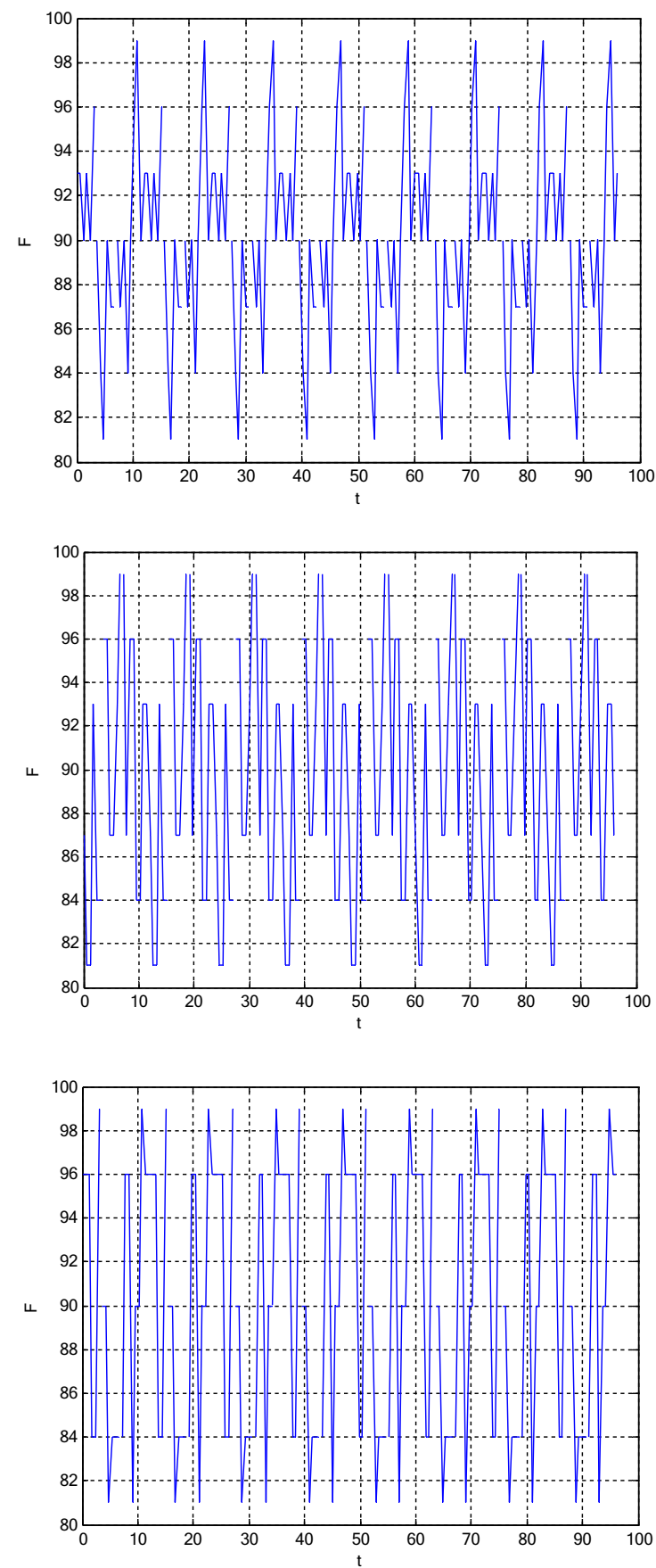

Fig. 9 Additional loads on the platform due to pumping unit under random conditions

The wave flow load and wind load are mainly issued with angles of $0^{\circ}, 45^{\circ}$ and $90^{\circ}$ to the y-direction (flow direction) based on a return period of 50 years. HPU load is set at the extreme condition that the 20 units work synchronously. The

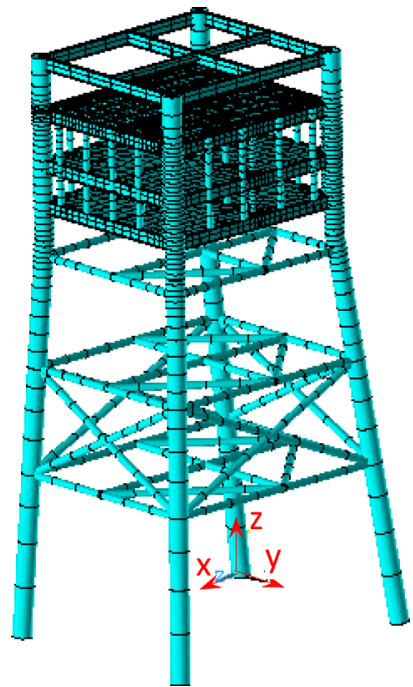

Fig. 10 Finite element model of the platform

deformation and stress extremes of the jacket are shown in Table 2. Here, the two conditions are adopted for comparison: I is the mechanical responses of jacket without HPU load, and II is the mechanical responses of jacket with HPU load.

To meet the requirements of safety, GB/T 712-2000 D36 specification steels whose yield strength is $345-360 \mathrm{MPa}$ are adopted to those pipes with a diameter of $\geq 406 \mathrm{~mm}$. And GB/T 712-2000 E36-Z35 specification steel with a yield strength of 345-360 MPa is selected for the Z-direction pipes. From Table 2, when HPUs work, the maximum stress of the jacket under extreme working conditions is $83.2 \mathrm{MPa}$, which is increased by $5.18 \%$ to the condition when HPUs are not working, and the safety coefficient is reduced by $4.93 \%$ from 4.55 to 4.33 . According to the Structural Design Specification of Offshore Steel Fixed Platform API RP 2A-LRFD, the safety coefficient should be greater than 4 (API 1993). Therefore, the overall strength of LD27-2 WHPB platform fully meets the safety requirement of the new rod pumping technology.

\section{The horizontal displacement of the platform}

According to the above finite element model, the extreme horizontal displacement of LD27-2 WHPB platform under the combined dynamic load is $47.2 \mathrm{~mm}$ and $38.1 \mathrm{~mm}$ at the top of platform and the sea level, respectively. The horizontal displacement of the middle platform and the lower platform can be calculated according to the relationship in Fig. 11. The relative horizontal displacement difference between the middle platform and the lower platform is about $4.14 \mathrm{~mm}$ under 
Table 2 Mechanical behavior of platform under combined conditions

\begin{tabular}{|c|c|c|c|c|c|c|}
\hline \multirow[t]{2}{*}{ Incident angle (loading condition) } & \multicolumn{2}{|l|}{$0^{\circ}$} & \multicolumn{2}{|c|}{$45^{\circ}$} & \multicolumn{2}{|l|}{$90^{\circ}$} \\
\hline & I & II & I & II & I & II \\
\hline Max deformation (/mm) & 34.4 & 36.3 & 37 & 39 & 37.2 & 39.5 \\
\hline Max stress (/MPa) & 70.2 & 75.5 & 78 & 82.1 & 79.1 & 83.2 \\
\hline
\end{tabular}

I-platform weight + wave flow load + wind load

II-platform weight + wave flow load + wind load + HPU working load

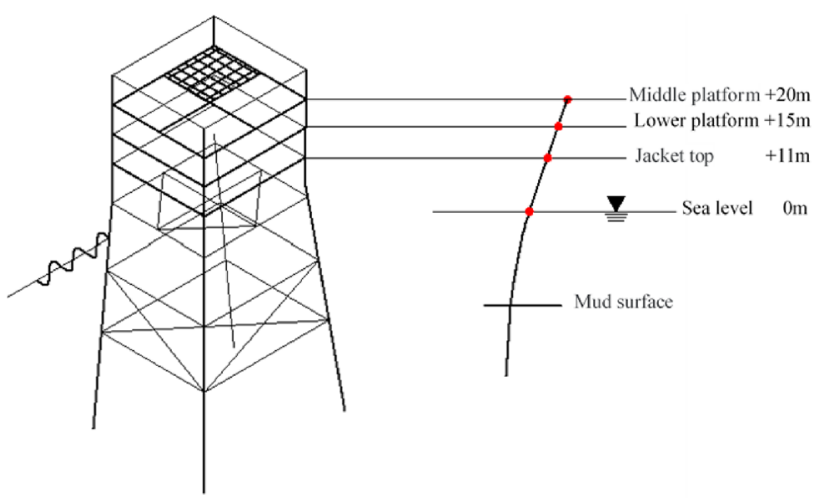

Fig. 11 Diagram of horizontal displacement of jacket platform with different stories

50 years of extreme sea condition, which is far less than the suspended point projection threshold of pumping unit according to API standard $(28 \mathrm{~mm})$.

\section{Conclusion}

To meet the need for high-efficient offshore heavy oil recovery and promote the new technology of offshore rod pumping, a mechanical behavior study of the LD27-2 WHPB platform under additional HPU load is carried out. The distribution of the combined HPU load accords with the classical probability model. The combined load on the platform reaches its minimum when the 20 units are completely desynchronized, while the load maximizes when the units are fully synchronized. In other conditions, the combined loads accord with different sine waves after stabilizing, but the periods are all $12 \mathrm{~s}$. The finite element analysis of LD27-2WHPB platform shows that the safety of platform based on extreme conditions with surface velocity as the main extremum is reliable and reasonable. Under the combined action of wave flow load, wind load and extreme HPU load, the maximum stress on jacket is $83.2 \mathrm{MPa}$, and the safety coefficient is 4.33 , indicating the overall strength of LD27-2 WHPB platform meets the safety requirement (safety factor marine engineering structure is greater than 4 ).
Acknowledgements Financial support was provided by the Fundamental Research Funds for the Central Universities (20CX02308A) and the Opening Fund of National Engineering Laboratory of Offshore Geophysical and Exploration Equipment. This study was also supported by National Science and Technology Major Projects of Oil and Gas (Grant Nos. 2016ZX05066, 2016ZX05042).

Open Access This article is licensed under a Creative Commons Attribution 4.0 International License, which permits use, sharing, adaptation, distribution and reproduction in any medium or format, as long as you give appropriate credit to the original author(s) and the source, provide a link to the Creative Commons licence, and indicate if changes were made. The images or other third party material in this article are included in the article's Creative Commons licence, unless indicated otherwise in a credit line to the material. If material is not included in the article's Creative Commons licence and your intended use is not permitted by statutory regulation or exceeds the permitted use, you will need to obtain permission directly from the copyright holder. To view a copy of this licence, visit http://creativecommons.org/licenses/by/4.0/.

\section{References}

API (1993) Recommended practice for planning, designing and constructing fixed offshore platforms-load and resistance factor design, 21st edn. API Production Department, Washington

Bodhayan D, Omprakash S, Jifeng W (2016) Characterization of leak rates in thermoplastic barrier valve seals under high static and cyclic pressure load. J Pet Sci Eng 145:279-289

Chandrasekaran S, Jain AK (2002) Dynamic behavior of square and triangular offshore tension leg platforms under regular wave loads. Ocean Eng 29(3):279-313

Chang ZY, Yu YQ, Qi YG (2017) Study on dynamic characteristics of hydraulic pumping unit on offshore platform. China Ocean Eng 31(6):693-699

Feng P, Wang ZJ, Tian WM (2008) Hydrological risk assessment of long-distance water transfer system based on the two-dimensional Gumbel distribution. J Catastrophol 23(1):23-26

Guo YH, Zhou XH, Li JP, Ling YX, Yang JM (2010) Crude features and origins of the Neogene heavy oil reservoirs in the Bohai Bay. Oil Gas Geol 31(3):375-380

Li P, Liu ZL, Zou JH, Liu Y, Yu JF, Fang YT (2016) Injection and production project of pilot test on steam huff-puff in oilfield LD27-2 Bohai Sea. Acta Pet Sin 37(2):242-247

Mangal L, Idichandy VG, Ganapathy C (2001) Structural monitoring of offshore platforms using impulse and relaxation response. Ocean Eng 28(6):689-705

Ou JP, Duan ZD, Xiao ZD (2003) Structural safety assessment of offshore platforms. Science Press, Beijing 
Ren WX, Zong ZH (2004) Output-only modal parameter identification of civil engineering structures. Struct Eng Mech 17(3-4):429-444

Shariatinia Z, Haghighi M, Feiznia S, Alizai AH (2013) Hydrocarbon migration in the Zagros Basin, offshore Iran, for understanding the fluid flow in the Oligocene-Miocene carbonate reservoirs. Russ Geol Geophys 54(1):64-81

Tang XX, Ma Y, Sun YT (2011) Research and field test of complex thermal fluid huff and puff technology for offshore viscous oil recovery. China Offshore Oil Gas 23(3):185-188

Wang SQ, Liang B (2013) Wave mechanics for ocean engineering. China Ocean University Press, Qingdao

Xu YH (2013) Study of environmental multi-loads combination for Jacket platform design in the Bohai area. Ocean University of China
Yan HB (2016) Reliability and risk assessment for structures and equipment of offshore platforms. ZheJiang University

Yasser E, Mostafa M, Hesham E (2003) Response of fixed offshore platforms to wave and current loading including soil-structure interaction. Soil Dyn Earthq Eng 24(4):357-368

Yu YQ, Chang ZY, Qi YG, Xue X, Zhao JN (2016) Study of a new hydraulic pumping unit based on the offshore platform. Energy Sci Eng 4(5):352-360

Zhou SW, Zeng HY, Li QP (2015) Research report on development strategy of Marine energy science and technology. Beijing

Publisher's Note Springer Nature remains neutral with regard to jurisdictional claims in published maps and institutional affiliations. 